\title{
It takes a community to raise a hydrologist: the Modular Curriculum for Hydrologic Advancement (MOCHA)
}

\author{
T. Wagener ${ }^{1,2}$, C. Kelleher ${ }^{1}$, M. Weiler ${ }^{3}$, B. McGlynn ${ }^{4}$, M. Gooseff ${ }^{1}$, L. Marshall ${ }^{4}$, T. Meixner ${ }^{5}$, K. McGuire ${ }^{6}$, \\ S. Gregg ${ }^{1}$, P. Sharma ${ }^{7}$, and S. Zappe ${ }^{8}$ \\ ${ }^{1}$ Department of Civil and Environmental Engineering, The Pennsylvania State University, University Park, USA \\ ${ }^{2}$ Department of Civil Engineering, University of Bristol, UK \\ ${ }^{3}$ Institute of Hydrology, University of Freiburg, Freiburg, Germany \\ ${ }^{4}$ Department of Land Resources \& Environmental Sciences, Montana State University, Bozeman, USA \\ ${ }^{5}$ Department of Hydrology and Water Resources, University of Arizona, Tucson, USA \\ ${ }^{6}$ Department of Forestry, Virginia Tech, Blacksburg, USA \\ ${ }^{7}$ Instructional Systems Program, Department of Learning and Performance Systems, The Pennsylvania State University, \\ University Park, USA \\ ${ }^{8}$ The Leonhard Center, College of Engineering, The Pennsylvania State University, University Park, USA
}

Correspondence to: T. Wagener (thorsten@engr.psu.edu)

Received: 6 February 2012 - Published in Hydrol. Earth Syst. Sci. Discuss.: 22 February 2012

Revised: 30 July 2012 - Accepted: 20 August 2012 - Published: 21 September 2012

\begin{abstract}
Protection from hydrological extremes and the sustainable supply of hydrological services in the presence of changing climate and lifestyles as well as rocketing population pressure in many parts of the world are the defining societal challenges for hydrology in the 21 st century. A review of the existing literature shows that these challenges and their educational consequences for hydrology were foreseeable and were even predicted by some. However, surveys of the current educational basis for hydrology also clearly demonstrate that hydrology education is not yet ready to prepare students to deal with these challenges. We present our own vision of the necessary evolution of hydrology education, which we implemented in the Modular Curriculum for Hydrologic Advancement (MOCHA). The MOCHA project is directly aimed at developing a community-driven basis for hydrology education. In this paper we combine literature review, community survey, discussion and assessment to provide a holistic baseline for the future of hydrology education. The ultimate objective of our educational initiative is to enable educators to train a new generation of "renaissance hydrologists," who can master the holistic nature of our field and of the problems we encounter.
\end{abstract}

\section{Introduction}

In this paper we review the current state of hydrology education based on community surveys and based on our own personal experiences. We identify shortcomings, challenges and opportunities, and outline a way forward in which education can facilitate the advancement of hydrology in both research and practice. We support this vision with practical examples of our Modular Curriculum for Hydrologic Advancement (MOCHA) project in which we implement and test this proposed community-based way forward.

\subsection{From hydrology to hydrologist skill needs}

Hydrology deals with the occurrence, circulation and distribution of water on earth, including its chemical and physical properties, and investigates the spatio-temporal storages and fluxes of water (in all its forms) in the terrestrial, oceanic, and atmospheric components of the global water system (US National Research Council, 1991; Dingman, 2002). Hydrology originated as an engineering discipline mainly focused on problems such as estimating extremes for hydrologic design applications (Chow et al., 1988). In time, the role of hydrology expanded, not only due to increasingly larger scales of study, but also due to the necessary inclusion of 
chemical and biological aspects of the hydrological cycle through topics such as water quality and ecosystem functioning (Eaglson, 1970, 2005; Dunne and Leopold, 1978; Mollinga, 2009). Today, the societal need for water, human security, and ecosystem function in a rapidly changing world requires, among other things, quantitative hydrological understanding that creates the necessary predictive capability across space- and time scales (Milly et al., 2008; Wagener et al., 2010). The wide range of investigation scales and the importance of understanding the role of water in the context of societally relevant endpoints, e.g., water supply for energy or food production, highlight the interdisciplinary nature of hydrology (Hendricks, 1962; King et al., 2012). The societal importance of water is likely to attract students with widely different backgrounds to the field of hydrology (Eagleson et al., 1991), either as a major field of study, or in support of a related discipline such as ecology, meteorology or soil science. Nash and colleagues already described the role of water as a connector and hence the need for hydrologists to be central in interdisciplinary teams. "It is likely that, for the foreseeable future, major problems involving the interaction of man with the hydrological environment on the global scale will increasingly require the attention of teams of scientists from many disciplines, including that of the scientifically trained hydrologist" (Nash et al., 1990).

Societal demands for hydrologic inquiry and problem solving will continue to erode the separation between science and engineering approaches to hydrology. Engineering solutions to hydrological problems in a nonstationary world will increasingly rely on mechanistic solutions, rather than empirical ones that depend on the assumption of stationarity, which are currently still an assumption made in many engineering hydrology methods (e.g., Milly et al., 2008). At the same time, scientists working in the field of hydrology will increasingly be pushed towards inquiry directly relevant to societal issues, which has important consequences, e.g., for the relevant scale of study. "Research topics come from societal needs as much as they come from the flow of scientific ideas and technological breakthroughs" (Eagleson et al., 1991; see also LeDee et al., 2011).

\subsection{From hydrology skill needs to hydrology education}

Hydrology is slowly escaping the dominance of empiricism by developing a greater scientific basis since the second half of the 20th century when it became clear that deeper scientific understanding was needed to solve water resources questions (Eagleson, 1970; Dunne and Leopold, 1978), and that a consideration of biogeochemical cycles was required to investigate water quality issues (Sopper and Lull, 1965; see discussion in McGuire and Likens, 2011). Viewing hydrology as a geo- and environmental science, rather than an engineering problem-solving discipline, provided an impetus for the study of hydrology as a unified field of natural science (Nash et al., 1990). Scientific hydrology as such has three major stages (after Nash et al., 1990): (1) careful observation of a phenomenon, (2) quantification and conceptualization, and (3) quantitative prediction.

A hydrologist who is to master all three aspects of scientific hydrology has to be well equipped with practical experience in observing and measuring hydrological variables, with in-depth process understanding and with the knowledge of how to translate this insight into quantitative theory. Finally, he or she needs to be able to build and utilize models to make actual predictions. Training such a holistic hydrologist requires a coherent and comprehensive science (Nash et al., 1990). Wagener et al. (2007) surveyed the approaches and opinions of hydrology educators and concluded that the field does not yet present itself in such a coherent way, leading to hydrologists with a restricted or uneven background. And even if such a coherent image could be found at this time, the increasing impact of climate change (largely propagated to societally relevant endpoints through the hydrological cycle) and the deepening footprint of human activity challenge the suitability of many of our methods, while also creating an exceptional opportunity for educational advancements (Firth, 1999; Wagener et al., 2010; LeDee et al., 2011). An older statement that "the present structure of hydrological education, generally tailored to the needs of specialized non-hydrological disciplines, is ill-fitted to cope with present and future requirements" (Nash et al., 1990) seems to unfortunately still hold true. "Hence, if we are not paying merely lip service to the science of hydrology, we should make an effort to provide it with an adequate educational basis..." (Klemes quote in Nash et al., 1990). So how do we achieve a coherent image of hydrology as an educational subject in the presence of these new demands?

\subsection{Opportunities through open education}

Next to the societal needs discussed above, there are other opportunities and developments outside the field of hydrology that make this a very favorable moment to advance and revitalize standards for hydrology education. Rather than following other fields, hydrology education could actually become a trendsetter in educational advancement due its interdisciplinary (given the use of methods from other established fields in hydrology) and problem-driven nature, which demand educational advancement more than other fields of study. An additional important characteristic is the placebased nature of hydrology. Local knowledge and experience are required to tailor general methods so that they become useful for problem solving in individual places. Hydrology education therefore requires the integration of knowledge and expertise from different fields, as well as the tailoring of methods to the characteristics of specific locations - or at least types of locations. These characteristics make hydrology a prime candidate for the use of Internet-based strategies to develop education material. 
The strong push for open education and open educational resources is therefore a very relevant advancement for the evolution of hydrology education (Mogk and Lee, 1997; McMartin, 1999; Muramatsu, 2000; Muramatsu et al., 2000; Manduca et al., 2001; Baraniuk et al., 2002, 2004). Projects such as edX, Connexions, MERLOT, OpenCourseWare Consortium, DLESE, NSDL, NEEDS or the NWS COMET program offer freely available course material that can be downloaded by everybody. However, availability of material does not equal uptake and utilization. Hydrology material might often only represent a small component of a large database of teaching materials, often produced for a student in a specific field of study (e.g., geology or civil engineering), developed by a single instructor with particular training and preferences, etc. and therefore not supporting the push for a holistic approach to hydrology education that is required. Also, constructive criticism and continuous refinement of such material is critical for improved hydrologic education standards and to enhance scientific community use. Successful examples of community-developed tools and materials already exist. One interesting community (bottom-up) development is the Linux operating system. The community-based development of this software through constructive criticism and error correction brought about one of the most widely used operating systems in the world (Lee and Cole, 2003). While everybody can contribute software to advance Linux, each contribution is carefully reviewed to ensure high quality of all submissions. How can such a controlled community-based development approach be transferred to hydrology education?

\section{Past assessments and current state of hydrology education}

The state of hydrology education has been reviewed multiple times in past (e.g., Wilm, 1957; UNESCO, 1972, 1974; Nash et al., 1990; Eagleson et al., 1991; MacDonald, 1993; James, 1993). One of the most prominent reviews of hydrology as a whole can be found in the so-called Blue Book from 1991, in which Eagleson et al. (1991) identified the following needs for hydrology education:

- Organization of a solid (perhaps senior-level) undergraduate course in scientific hydrology.

- Definition of hydrology education as a unified field of natural sciences.

- The need for a coherent and comprehensive science in its educational image.

- The inclusion of human activity into hydrology.

- More field and laboratory experience.

We do not believe that these needs have yet been fulfilled, but rather that some of the issues have become more rather than less problematic. With respect to their last point, Eagleson and colleagues were of the opinion that that lack of field and laboratory experience had already "reached crisis proportions in many universities" (Nash et al., 1990; see also Philip, 1992; Trop et al., 2000; and Pearce et al., 2010). The value of field research for enhancing scientific understanding in hydrology is undisputed and has been demonstrated through a wide range of educational studies (Carlson, 1999; de Wet, 1994; Dunnivant et al., 1999; Hudak, 1999; Trop et al., 2000), but decreasing funding and increasing student numbers have further reduced the availability of hands-on experience during undergraduate education at many universities. How to deal with this issue remains an unsolved problem (though see ideas of Rodhe, 2012). Our own work has focused on advancing the other four points though, and we will concentrate the rest of the paper on them.

A recent survey revealed a level of incoherence in what constitutes hydrology education at this time. Wagener et al. (2007) surveyed over 150 hydrology educators at universities in the US (71\%) and in Europe. About $35 \%$ of educators surveyed were at the time teaching in engineering and the rest in science departments. $43 \%$ reported engineering as their highest degree, while the others reported various science degrees. The survey results can be summarized as follows: (1) class characteristics (Fig. 1a): most survey participants taught relatively small classes with up to 25 students (54\%). Only $9 \%$ of all instructors taught classes larger than 50 students (generally in engineering). Participants described their classes as fitting into one of four categories: general hydrology $(43 \%)$, surface water hydrology $(30 \%)$, groundwater hydrology $(17 \%)$, and water resources management $(10 \%)$. (2) Teaching material: with respect to the materials used for their classes, about $40 \%$ of all survey participants reported that they do not use any textbook as a class resource. In general, all survey participants used a wide range of material to create their lectures. $68 \%$ of the participants who did use a primary textbook took $50 \%$ or less of their material from this primary text. (3) Preparation time (Fig. 1b): most participants in the survey stated that they spent $3-5 \mathrm{~h}$ to prepare $1 \mathrm{~h}$ of actual lecture time when teaching a course for the first time. A large number of respondents still spend $1-2 \mathrm{~h}$ of preparation per lecture when teaching the course in subsequent years.

The variability in material used and the extensive preparation time needed to organize this material to form a coherent lecture suggest that hydrology does not yet possess a common basis that would make preparing such a course easy. The survey therefore concluded that "hydrology educators are challenged to identify common principles, core knowledge, and approaches that should be included, in addition to areas where clear consensus is lacking" (Wagener et al., 2007). 

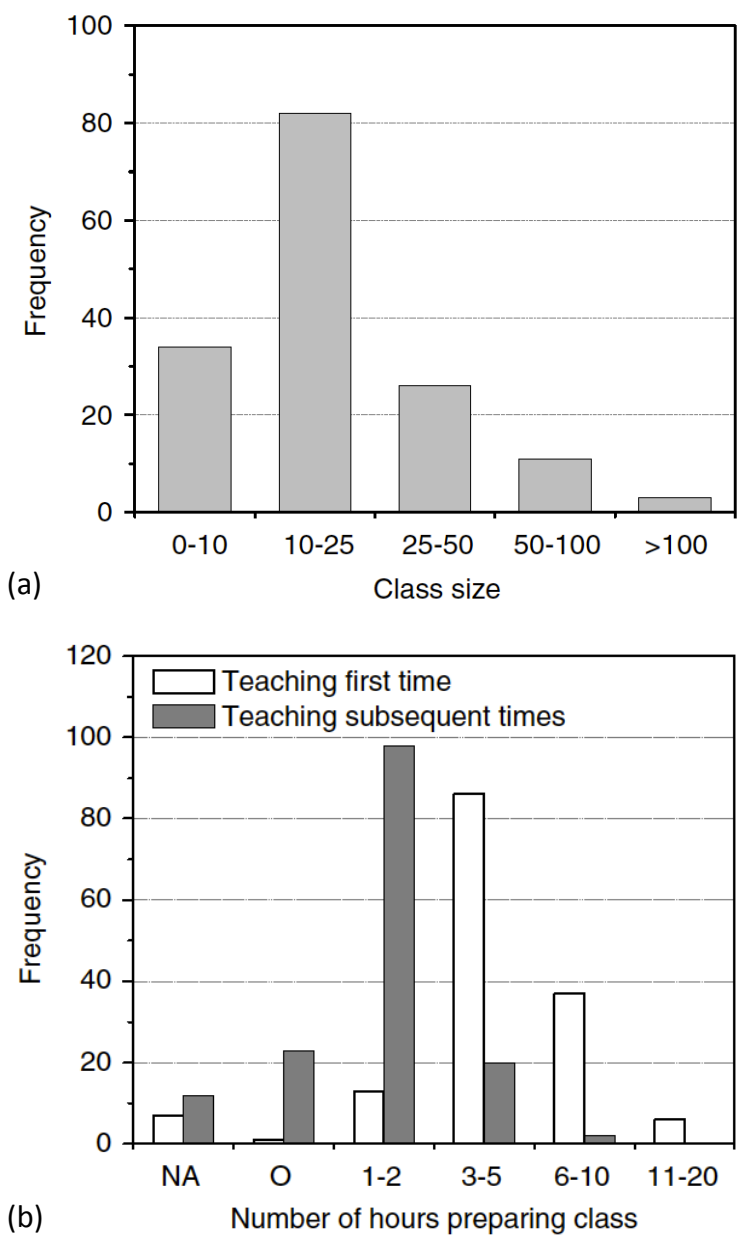

Fig. 1. Survey results showing class sizes and preparation times of hydrology educators (from Wagener et al., 2007).

\section{Current limitations in hydrology education}

\subsection{Hydrology education assessment}

Most students have their first encounter with the hydrologic cycle time in high school, if not earlier. Recent studies, however, showed that the perception of the water cycle in the mind of many high school students lacks its dynamic, cyclic and systemic aspects, is incomplete and will include misconceptions (Ben-zvi-Assarf and Orion, 2005; Dickerson et al., 2006). Ben-zvi-Assarf and Orion (2005) concluded that this is a consequence of the traditional disciplinary approach to science teaching based on their survey of 1000 junior high school students (7th-9th grade) from six urban schools in Israel. Some of these misconceptions prevail even for university students (Dickerson et al., 2005), and may even be enhanced due to errors or incomplete representations in general geoscience textbooks (Wampler, 1997, 2000). The starting point for hydrology education at the university level is therefore at best an incomplete picture of the hydrological cycle. At the same time, the increasing coverage of waterdriven issues in the news (floods, droughts, impacts of climate change, pollution) and the personal experience of extreme weather events have enhanced the public's appreciation for water-related issues.

There also seems to be an increasing interest in hydrology education research (Kastens et al., 2009). Studies have for example assessed the value of computing in conveying concepts of data analysis or modeling in hydrology (Elshorbagy, 2005; Hossain and Huddleston, 2007; Wagener and McIntyre, 2007; Schwenk et al., 2009; Aghakouchak and Emad, 2010), which is less straightforward than it might appear (Whiteman and Nygren, 2000). Others have attempted to use watersheds as an integration scale outside hydrology (Salvage et al., 2004), or tested how the use of physical model can reduce misperceptions of hydrological processes (see references in Rodhe, 2012). In addition to the increasing societal recognition of water-related issues and threats, there are opportunities to enhance hydrology education by linking it to popular concepts such as sustainability or millennium development goals, e.g., access to clean water (Mihelcic et al., 2008) or risk in regard to natural hazards (Boynton and Hossain, 2010). Despite these opportunities, there are continued calls for necessary change to hydrology education (Clifford, 2002; Howe, 2008; Ledley, 2008; Manduca et al., 2008; Wagener et al., 2010; Thompson et al., 2011), to satisfy the demands of a strong job market for hydrologists (van Vuren et al., 2009; Zimmerman, 2009; Milano, 2010).

So what is lacking in hydrology education today? The continued separation of science and engineering approaches to hydrology education and the lack of hands-on fieldwork have already been mentioned. However, we are convinced that an integration of qualitative and quantitative aspects into a holistic teaching approach to hydrology will continue to propagate through the educational system. There are other basic issues, such as a lack of a well-grounded applied mathematical understanding of many (even engineering) students in hydrology (Kavetski and Clark, 2011). And there is the need for students to develop a general appreciation for the heterogeneity of hydrologic systems around the world (e.g., Shaw and Walter, 2012), which is difficult to convey with traditional means. Hydrology education, especially in engineering departments, has historically focused on teaching established solutions to current (and sometimes past) problems. There is, however, an urgent need to focus on teaching an evolving skill set with a strong scientific basis that can be adapted to solve new problems with new tools and to understand new phenomena (Wagener et al., 2010). New interdisciplinary approaches to education are required, and we need the material to support such an education inside and outside the classroom. 


\subsection{Practical problems when teaching an undergraduate hydrology course}

Hydrology is commonly taught in different departments across campus and only few programs fully focus on hydrology and water resources education for undergraduate students (e.g., at the Universities of Arizona and Freiburg). The generally small number of undergraduate students enrolled in these dedicated programs indicates that the majority of hydrologists are educated within some other primary discipline. One consequence of this fact is that students are likely to encounter only a single hydrology class during their undergraduate studies. This limited exposure means that much has to be achieved - in terms of introducing an interdisciplinary field - in a single course. Here we discuss common issues such a course is likely to encounter.

Any course is likely to be biased towards the instructor's expertise (How was he/she taught and what is his/her research field?), towards the department (What are the course prerequisites and traditions? How does the course connect to other courses, e.g., a capstone class? Do the students have a more qualitative or quantitative background?), and towards the material used (Who wrote the textbook, with what kind of background and for whom?). As a result, the focus of the class is typically not consistent with the needs of an inherently interdisciplinary subject. Educators who want to break this cycle face a monumental task that includes the collection and preparation of material from multiple textbooks and from different disciplines. Following this collection effort, any hydrology educator has to self-educate with respect to multiple new topics before the collage of material can be integrated into a single course. Furthermore, it is often necessary to regularly modify class materials by including new discoveries or changes to hydrologic science as they are published and used by the broader hydrologic community. This is more difficult than it seems at first glance because it takes significant time and effort to learn key material and concepts outside of our immediate sub-disciplines. Additionally, implementing good classroom practice involving active learning through creation of case studies, or through cooperative and problem-based learning, is time-consuming (Lynn Jr., 1999; Smith et al., 2005).

The successful execution of such a task is especially difficult for educators in their first academic position (typically lecturer or assistant professor), since such an effort has to be balanced with the writing of papers and proposals, the supervision of students, and other demands on young academics.

This problem exists despite the fact that a range of excellent hydrology textbooks is available. Examples of popular textbooks (see extended listing in Wagener et al., 2007) include Dingman (2002), Hornberger et al. (1998), Bras (1990), Beven (2000, 2010), Dunne and Leopold (1978), Brooks et al. (2003), Hewlett (1982), Ward and Trimble (2003), Chow et al. (1988), Brutsaert (2005), Shaw et al. (2010), and Hendriks (2010). However, none of these books fully satisfies the broad requirements discussed above, given that the authors typically have the same subjectspecific bias mentioned, and because textbooks are typically static and do not evolve to integrate new research results, new measurement techniques, new exercises, or new topics - a problem that is significant in the quickly evolving field of hydrology. The transition from general theory to specific applications tailored to local physical and climatic settings is also typically not adequate.

We summarize our view of the limitations of currently available material for hydrology education and their consequences on teaching below:

1. The time-consuming task of finding and incorporating material into lectures leads to an unwanted focus on material preparation. This time is taken away from time that could be spent on actual teaching preparation (how best to teach the material to a specific group of students). While the Internet has made finding new material a quicker process (especially multi-media material), McMartin (1999) found that faculty have difficulty using Internet resources in their teaching, specifically because of lack of time to learn about the material, difficulties of finding usable material, and lack of training on how to use the material. There is also often a lack of background information on and description of the material one finds on the web.

2. Information is rarely available about how to best convey this particular knowledge to students in the classroom. Pedagogical guidelines and standards normally do not accompany available course materials, even though they are vital for new educators.

3. No single suitable textbook exists that can accommodate the interdisciplinary nature of hydrology (Groves and Moody, 2007). A large number of textbooks have to be distilled and it is often daunting to extract the relevant information. Our own survey (Wagener et al., 2007) showed that common textbooks used by educators do not only include different hydrology texts, but books on meteorology, soil science, probability/statistics, fluid mechanics and others.

4. A collage approach of collecting material leads to a lack of continuity in the material presented to the students. Should the instructor decide to adopt a single (main) textbook (despite the abovementioned problems), so that students can read the relevant chapter before (or after) a certain topic is covered, other limitations become imminent, mainly the need to (reasonably) follow the linear structure provided by the textbook.

\subsection{A community-driven way forward}

We identified these problems and issues discussed above several years ago and have since worked on defining a way 
forward to overcome these challenges. A significant step forward can, in our opinion, only be achieved through a concerted community-driven effort. The need for creating a holistic hydrology curriculum is far beyond the ability of an individual hydrologist, without us wanting to diminish individual contributions through excellent existing textbooks. As a response to this problem, we developed and tested a community platform to create a hydrology curriculum. We refer to this educational model for hydrology as the Modular Curriculum for Hydrologic Advancement or MOCHA, which we describe in detail below.

\section{Hydrology education 2.0 - the Modular Curriculum for Hydrologic Advancement (MOCHA)}

The Modular Curriculum for Hydrologic Advancement (MOCHA) is establishing an online faculty learning community for hydrology education and a modular hydrology curriculum based on modern pedagogical standards. "The purpose of creating faculty-learning communities is to provide colleagues with a means to learn from one another unconstrained by barriers of time, distance, technology, and geographic location" (Puzniak et al., 2000). A community can be defined as " $a$ dynamic whole that emerges when a group of people share common practices, are independent, make decisions jointly, identify themselves with something larger than the sum of their individual relationships, and make long-term commitments to the well-being of the group" (Shaffer and Anundsen, 1993). MOCHA currently (July 2012) has 399 members from 43 countries. The majority of users are from the USA (39\%) and Europe (41\%), though $11 \%$ of members are from Asia or Africa. The initial objective of the MOCHA module development activity is to create a continuously evolving core curriculum that overcomes traditional disciplinary biases and is freely available to, and developed and reviewed by the worldwide hydrologic community. The project is implemented using a web portal to support this community-driven curriculum development (www.mocha.psu.edu).

MOCHA is advancing educators' abilities to challenge students to address complex and interdisciplinary problems across the field of hydrology. It provides hydrology educators with the tools and materials to be efficient and successful teachers, while enabling students to gain (in-class) access to current, peer-reviewed, high quality educational resources. Diverse contributors are working collaboratively to create material that addresses a wide range of student and educator learning and teaching styles and needs (Fig. 2). Furthermore, MOCHA is creating and institutionalizing an interdisciplinary hydrology learning community that can serve as a model for other STEM (science, technology, engineering, and mathematics) fields.

The MOCHA project directly addresses the issues raised in previous sections by providing the hydrological community with free teaching material available in an easily accessible and classroom-friendly format. The community development of material facilitated through MOCHA provides us with an opportunity to test what can be achieved in such a community setting. Below we discuss the specific characteristics of the MOCHA modules.

\subsection{Control volume approach as integrating principle}

Students often perceive hydrology as a random collection of empirical equations that describe a wide range of different processes. This lack of coherence hinders the development of a holistic quantitative picture of the field of hydrology and can lead to a dislike of the topic, certainly in engineering students. Rather than offering a consistent approach to solve hydrological problems, most classes and textbooks demand that the students learn individual solutions for specific problems. Few textbooks provide a consistent approach for deriving equations of different hydrological processes. Chow et al. (1988) is the first hydrology textbook (to our knowledge) that does offer a consistent approach by using a control volume approach throughout. Despite its age, it remains a widely used hydrology textbook (Wagener et al., 2007). We propose, similar to Chow et al. (1988), to use a control volume (CV) approach to achieve consistency (Fig. 2a), and to use the Reynolds transport theorem as the analytical starting point to describe fluxes in this $\mathrm{CV}$ context. Engineering students will be familiar with CV theory from their fluid mechanics class, which is typically a prerequisite for hydrology. Using the same CV approach in hydrology creates a consistency, which helps the students to see that the same physical principles rule hydrology and that it is the simplifying assumptions made in the derivation of equations for different processes, which leads to the diversity of solutions found. The simple conceptual basis of the CV approach makes it also a very suitable tool to teach hydrology to students who are more restricted than engineering students in their mathematical abilities. There is no need to start with the explicit Reynolds transport theorem for non-engineering students; the basic idea that the change in storage equals input minus output can be conveyed without it.

\subsection{Pedagogical guidelines for lesson design}

Some universities will provide opportunities for young faculty members to receive teaching training. Or there might be general programs that offer such guidance, like the ExCEEd program of the American Society of Civil Engineers (ASCE) (http://www.ascedrive.org/exceed/). However, time constraints (a major issue for junior academics who are trying to get their research program started) or the lack of general infrastructure and senior mentors to support university teaching in less developed countries (Hughes, 2012) might still limit training opportunities. We therefore believe that it is crucial for an educational initiative such as MOCHA to 


\section{EXAMPLES OF MOCHA MODULE CHARACTERISTICS}

(a) Use of control volume approach for consistency

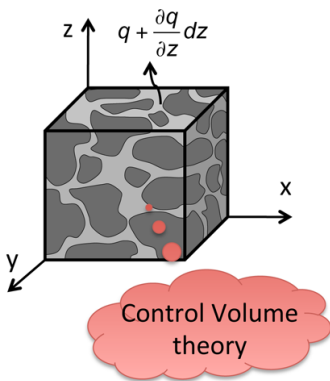

(b) The $A B C D$ of lesson design

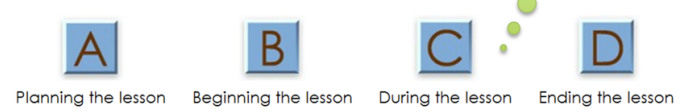

(c) Teaching notes to share experience

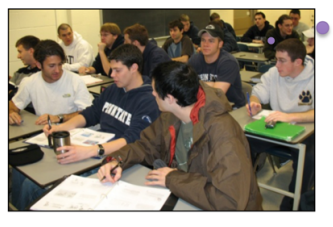
differently to the same material

Example from infiltration module: Prompt class to discuss how the infiltration curve of a gravel soil would be different than a clay soil, and to identify why these differences exist.

Fig. 2. Main characteristics of the MOCHA PPT modules.

propose a set of basic (but crucial) pedagogical guidelines as a foundation for hydrology educators everywhere.

As a first step toward addressing this need, we list 16 pedagogical guidelines as an $A B C D$ of lesson design (Fig. 2b). The lettering refers to the time period when the guidelines are valuable for the instructor in the preparation and teaching process: (A) planning the lesson, (B) beginning the lesson, (C) during the lesson, (D) ending the lesson. Table 1 lists the main points for good lesson design. These points are not necessarily specific to hydrology education, but provide a general reminder of good practice for instructors who previously received training, or provide a starting point for further reading if the instructor has not had such an opportunity.

\subsection{Teaching notes to share how we teach}

More problematic than general pedagogical guidelines, and generally unavailable, is access to specific guidance on how to teach the material at hand. The support needed here goes beyond reading textbook explanations of the material covered. While one could easily assume that the problem of finding suitable teaching material has gone away with the advancements made in Google web searches, this is not correct as already discussed in Sect. 3.2. Simply providing access to the material is insufficient. The time and effort needed to (d) Assertion and visual evidence design

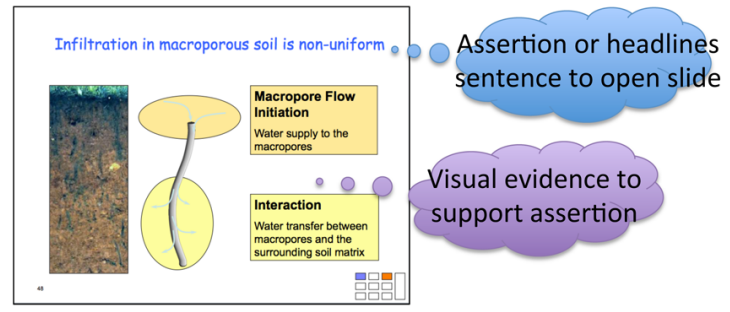

(e) In-depth learning slides Theory depth

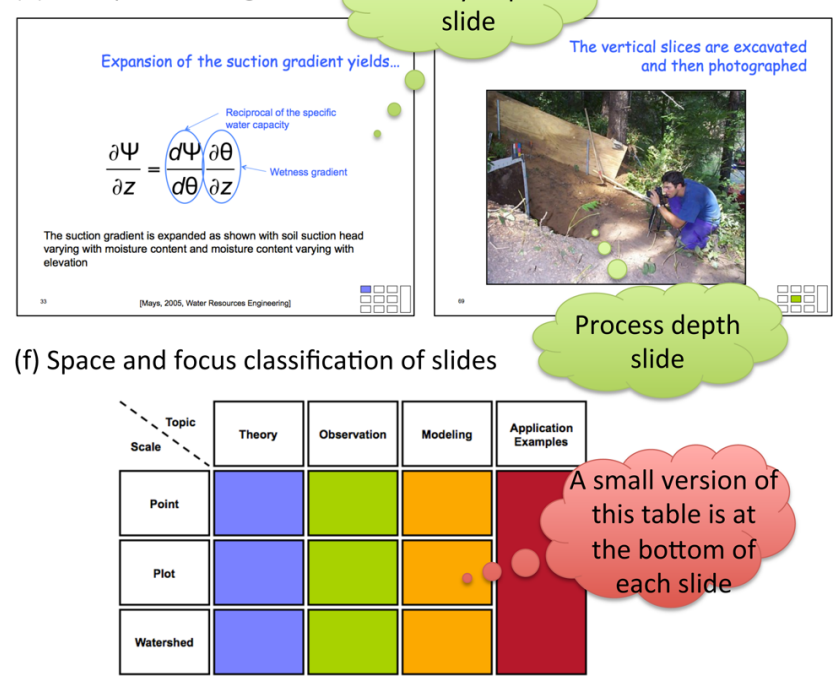

turn this material into an actual, effective lecture or into other types of learning material is still very high (see Fig. 1).

In addition to providing the material to be used in class, we therefore need to educate the instructor (where needed) on how to use the material. Teaching notes are the chosen solution to this problem in MOCHA (Fig. 2c). All MOCHA modules include teaching notes (in the notes section of PPT), which provide suggestions on how to convey the material presented on each slide. Such teaching notes allow the instructor to benefit from the experience gained by the module creators (or other module users). Teaching notes might include an opening question to a figure or a graph, a strategy to explain a difficult aspect of the material, or they could discuss a common stumbling block for the students to understand the material. The notes section of each slide also includes references with information about the material presented on the slide, so that instructors may refer to material sources when in search of guidance beyond the teaching notes.

\subsection{PowerPoint design based on education research}

While it might seem strange to some that we included a section on a specific software package here, we believe that the close link between teaching style and the way the material is conveyed warrants this discussion. Microsoft 
Table 1. The ABCD of lesson design (http://www.mocha.psu.edu/lesson-design).

A. Planning the lesson

(1) Identify the skills and knowledge your students are coming in with so you can address the appropriate level of content.

(2) Plan your lesson in approximately 20 min chunks of lecturing, interspersed with 5-10 min of activity (e.g., discussion or problem) to keep the students refreshed and engaged.

(3) Ensure that your slides and presentation materials are well designed and clear (see MOCHA template).

B. Beginning the lesson

(4) Begin every module/unit/lesson with a list of objectives for the lesson. Objectives help students to focus on what they have to learn and also provide a goal for the session.

(5) Objectives should be short, clear statements about what a student will be able to do at the end of a lesson. E.g., "Students will apply available measurement techniques (for properties, fluxes and states) including their limitations."

(6) Phrase objectives in $S M A R T^{*}$ terms - i.e., so that they are:

(a) Specific - avoid using words like understand or appreciate. Use an active verb that describes what students can do as a result of learning.

(b) Measurable - use concrete outcomes to frame student learning, i.e., "students will accurately describe problems related to XXX," as opposed to "students will appreciate problems related to XXX."

(c) Achievable - ensure that the objectives are achievable within the scope of the lesson, i.e., "students will solve problems related to XXX," as opposed to "students will solve problems."

(d) Relevant - this indicates that the objectives are relevant to the content being addressed. Avoid writing objectives about material that is not being addressed in the specific unit.

(e) Timely - this is not always needed, but is used to indicate any time frame attached to achieving the objective.

(7) Activate student attention and establish instructional purpose - if you grab student interest in the beginning, they are likely to pay more sustained attention throughout the lesson. For example, use a current problem or novel and paradoxical events related to the topic; make a clear link between the content and students' prior knowledge - tell them why it matters to them; make it clear how the present learning relates to other learning tasks.

(8) Provide a structure or an advance organizer for the information you want to present - use an outline or a chart or graphic to demonstrate what information you plan to present and in what sequence - this should help students identify what is coming next.

(9) Trigger students' previous knowledge about the topic - try to make connections between what students already know and the content you are trying to present. Students are likely to remember information better when they can link it to knowledge that they already have.

C. During the lesson

(10) Arouse interest and motivation throughout the lesson - relate the lesson objective to future job requirements and make instructional goals relevant to students' personal lives.

(11) Use different strategies to deliver information - useful strategies include using graphics or videos to enhance slides, using examples and metaphors to clarify concepts, presenting smaller and more simple chunks of information before presenting bigger and more complicated chunks of information, talking through the steps and reasoning involved in different procedures, and engaging students in small exercises and group work to solve problems and case studies.

(12) Focus attention - focus your attention on the students' reactions, and use teacher effect such as gestures, eye contact, animation, vocal inflection, enthusiasm, etc. to give students your feedback.

(13) Practice - give students the chance to practice what they have learned. Every 10-20 min or after every $\sim 5$ slides, insert some questions based on the material just presented. This gives students a chance to show what they have learned and also breaks up the monotony of a long lecture.

D. Ending the lesson

(14) Summarize and review - summarize and review what you have taught in order to reinforce the students' knowledge.

(15) Transfer knowledge to new settings - explicitly state how the newly learned information can be applied in different settings.

(16) Assess student knowledge - use a quick quiz or ask a series of questions to the students to assess student learning. Also, from students' feedback, you can evaluate your teaching and remediate your lesson plan for next time.

* Doran (1981) 
PowerPoint (PPT) is the most widely used presentation package and therefore our software of choice. We developed a general PPT template as the basis for each MOCHA module (Fig. 2d). In this manner we achieve seamless connectivity between modules through a common template, and a common look and feel that makes any collection of modules used in class appear as a single coherent set of lectures. It also enforces some of the pedagogical guidelines, e.g., through inclusion of a learning objective slide, interactive activities for students, etc.

The use of PPT has often been widely criticized: “... PowerPoint has a dark side. It squeezes ideas into a preconceived format, organizing and condensing not only your material but - inevitably, it seems - your way of thinking about and looking at that material" (Keller, 2004). The issue of how PPT shapes presentation styles and how this limits communication has been discussed in detail by Tufte (2003), who concludes the following: "In particular, the popular PowerPoint templates (ready-made designs) usually weaken verbal and spatial reasoning, and almost always corrupt statistical analysis." There are remedies to some of these issues and we utilize some that have been shown to significantly enhance memorization and learning using PPT (Alley, 2003). A main problem with PPT slides is that the design default tends to oversimplify and fragment the subject matter at hand. As a remedy for these problems, we use an assertion-evidence structure (Alley and Neeley, 2005). In this assertion-evidence design, a statement, assertion or headline is placed at the topic of the slide, in the area usually reserved for a short topic. Evidence to support this assertion is then placed in the body of the slide. This evidence should be visual whenever possible (e.g., images or graphs). For example, bulleted text can often be reduced to keywords supported by photographs or graphics. This is more interesting while it should not limit our ability to memorize the content, since we generally remember keywords, rather than full sentences anyway. Alley and colleagues have shown in multiple studies that such design and some additional design guidelines related to organization, typography and layout significantly increase audience interest and material retention (Alley et al., 2007; Garner et al., 2009, 2011).

\subsection{In-depth PPT slides for higher-level material}

It is not sensible to develop a single set of PPT slides suitable for all instructors and all types of students (engineering or science, junior or senior level, etc.). Providing material that is sufficiently rich and diverse so that it can be easily adapted to a wide range of courses, without being overwhelming in total volume, is therefore our goal. This adaptability is crucial if wide-scale adoption of MOCHA is the objective. Any MOCHA module therefore contains more slides than an individual instructor is likely to use. The level of depth that instructors choose for their students will depend on a range of considerations: their background, their familiarity with the material, their degree-granting department (science or engineering), and their year of study.

If each MOCHA module includes excess material, then it is also sensible to provide instructors with guidance on how to select the appropriate material for the students in their class. MOCHA modules therefore include (visually marked) in-depth slides that allow instructors to tailor the material to the specific needs and abilities of their students. For example, a derivation of Richards equation might be something to be included in some engineering or physics-based courses, while it may not be appropriate for science students. On the other hand, science students might want to gain more in-depth understanding about underlying processes. In-depth slides are color-coded depending on whether they refer to indepth study of theory or processes (Fig. 2e). The ease with which modules can be rearranged also supports the module use for courses in which hydrology is only a support topic, rather than the main focus.

\subsection{Classification of PPT slides by spatial scale and focus}

Differences in preferred course structure and teaching style between instructors became apparent during the development of the initial MOCHA modules. Subsequent discussions highlighted very quickly that the order in which different instructors' present material to their students varies widely. Some educators for example started with a discussion of processes and observations, and then added the mathematical treatment and the solving of problems, while others moved from local, to plot to catchment scale. We therefore strived to develop material that allows for an easy adaptation to different teaching structures. While it is generally accepted that different students have different preferred learning styles (Felder and Brent, 2005), different instructors also have different approaches to teaching (Felder and Silverman, 1988; Prince and Felder, 2006). The MOCHA material needs to accommodate these differences. Each MOCHA slide is classified in two ways to achieve this flexibility. First, we classified slides by the spatial scale (point, plot or catchment) to which the material on the slide refers. In addition, each slide is marked regarding whether it relates to theory, processes or observations. This information makes it easy for instructors to organize slides by scale or by focus, hence adapting the material to their own preferred style. This slide classification allows instructors to organize their lectures in PPT "Slide Sorter View" with very little effort (Fig. 2f), building additional efficiency into the process of lecture generation.

\section{Initial assessment of MOCHA}

Some preliminary assessment of initial MOCHA modules has already taken place. The Infiltration module was first assessed in three courses across the United States during 
(a) Large hydrology classes are typical in engineering, e.g. at the Pennsylvania State University

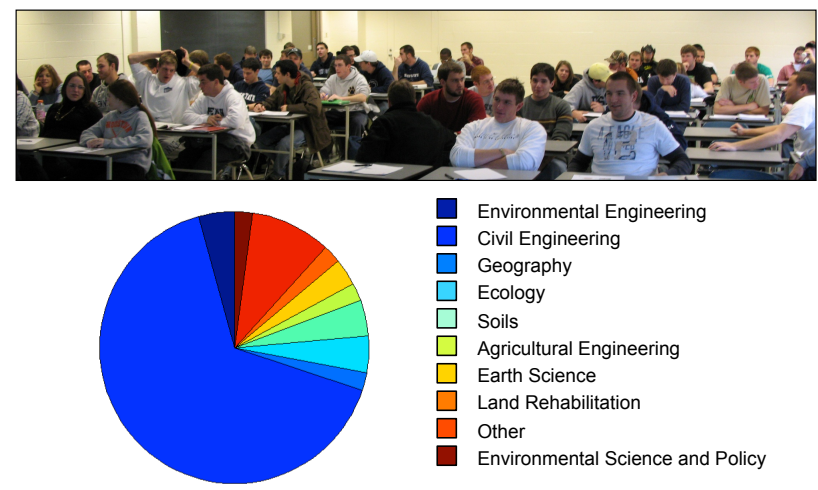

(b) Distribution of study majors for students participating in initial assessment

Fig. 3. Major disciplines for the 110 students included in the initial MOCHA module assessment.

the fall of 2008 to gain feedback from educators and students. Modules were taught in three different departments to evaluate a cross section of student and instructor backgrounds: Land Resources and Environmental Sciences (Montana State), Civil and Environmental Engineering (Penn State), and Environmental Sciences and Policy (Plymouth State). Following classroom use, students were referred to a website with a series of questions about their background and their opinions on the module.

Student backgrounds included several engineering and science disciplines (Fig. 3) and different years of study, including both graduate and undergraduate levels. A total of 110 students were surveyed. On the whole, students responded positively to the modules. Results from the three different courses were combined, and are presented in Fig. 4. The majority of students found the module material interesting (Fig. 4a) and indicated that they understood it (Fig. 4b). To assess the module pedagogy, specifically the learning objectives, we asked students whether the module learning objectives were clear. Figure $4 \mathrm{c}$ shows that students responded positively, with $74 \%$ in agreement. Another interesting result of the assessment was that $90 \%$ of the students (Fig. 4d) agreed that their instructor was comfortable using the module.

Since we established the MOCHA website, over $95 \%$ of MOCHA members have downloaded the Hydro-Ecology module, and almost all users have downloaded the Infiltration module. Additionally, over $60 \%$ of users have downloaded the Pedagogical Guidelines for designing a good lesson. During the fall of 2009, we informally polled the MOCHA community to measure whether and how modules were being used in the classroom. Responses indicated that the majority of professors were tailoring the module materials to their specific classes, using at least parts of the module to augment

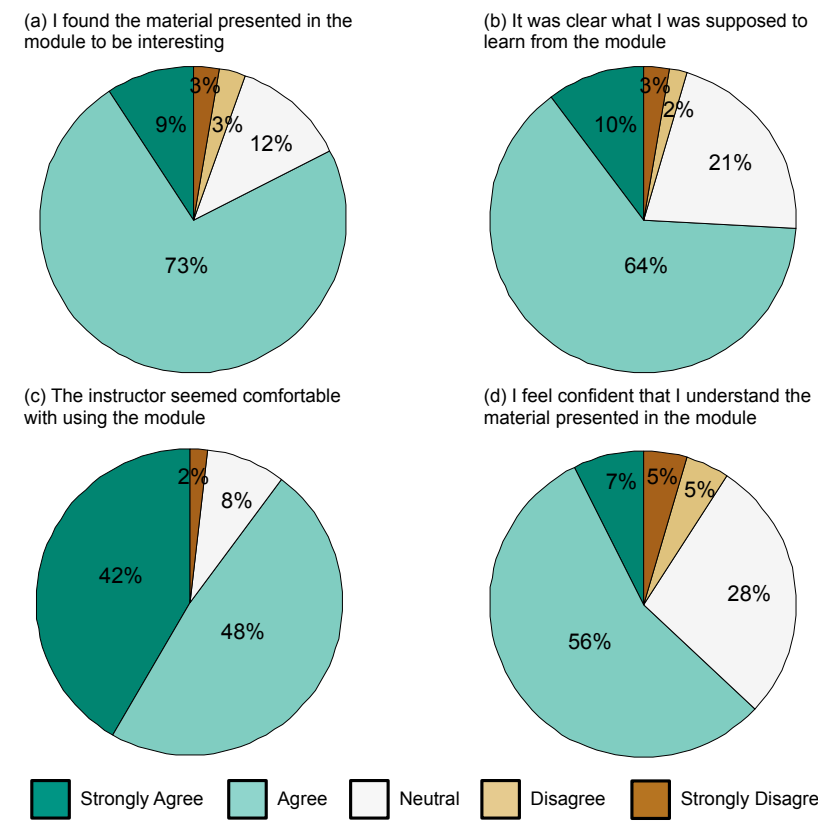

Fig. 4. Student responses from the initial MOCHA module assessment at Plymouth State (5 students), Montana State (27 students), and Penn State (78 students).

their own material. We assume that this partial use remains the most likely utilization of the modules until a full course is available through MOCHA.

\section{From MOCHA to a faculty learning community}

The current focus of MOCHA is the development of a modular curriculum for an upper level undergraduate course in hydrology - suitable for both science and engineering students. Such a course, developed, reviewed and evolved by a diverse group of educators would represent a first milestone towards the creation of an online faculty learning community in hydrology. Further future activities will include the development of a web portal that can facilitate review, assessment, and updating of modules; host multi-media elements to support different topics; provide metadata for the modules present, etc. Such cyber-infrastructure will be crucial for the longevity of the project (Merwade and Ruddell, 2012). Especially, this portal should host the following:

- Case studies that can be given to the students as homework assignments - individually or as groups. These cases should cover very different hydrologic applications (e.g., flood frequency analysis or the characterization of the hydrologic function of a catchment) and very different regions of the world.

- Multi-media elements that provide additional insight into measurement methods, into the diversity of 
catchments found around the world, and into more advanced guidance for programming models or to perform data analysis.

- Stand-alone modules (potentially even online modules), which contain material that the students should not study in the classroom, but by themselves. This material could for example include reviews of material that should have been covered elsewhere, e.g., basic statistics or mathematics.

- A model base with algorithms that the students can download and use to support their homework assignments or in term projects (Wagener et al., 2004). Such algorithms need to be accompanied by sufficient documentation and data examples.

- Examples of how to teach students in the field using adequate observation and measuring techniques. These examples could also be included as movies for students to watch and therefore provide access to a much wider range of methods than locally feasible.

\section{Conclusions and outlook}

The changing demands on hydrology as a science and as an engineering discipline offer an exceptional opportunity to advance hydrology education (Wagener et al., 2010). We need to enable the education of researchers and practitioners "who can better address the complex interactions within natural systems and between humans and the environment" (NSF AC-ERE, 2005). We need integrative educational platforms to bridge traditional disciplinary boundaries. In this paper, we review educational developments in hydrology up to now, take a look into the future, and present a communitybased framework in which we establish a faculty learning community centered around a modular hydrology curriculum (MOCHA).

We believe that such a project can have direct and significant implications for global hydrology education, as well as broader implications for our field as a whole. We see hydrology education as an opportunity to (1) create a baseline (even if it is shifting) by organizing our knowledge, (2) provide an overview of existing knowledge and knowledge gaps in hydrology, and (3) create a faculty learning community in which we collaboratively create the interdisciplinary education hydrology demands. We have made the initial steps towards achieving these goals. However, seeding an idea is only the beginning. Many good ideas in the area of education never achieve large-scale adoption (Baker, 2007; Henderson and Dancy, 2010). We believe that we have built the momentum to overcome this problem, and the growing MOCHA community supports this opinion. An active collaboration and interaction among the members will ultimately be required to fulfill our goal.
Acknowledgements. This work was supported by the US National Science Foundation through the CCLI Program under grant DUE 06335. Any opinions, findings, and conclusions or recommendations expressed in this paper are those of the authors and do not necessarily reflect the views of the US National Science Foundation. We thank Theodore Endreny and one anonymous reviewer for their helpful clarifying comments.

Edited by: S. Uhlenbrook

\section{References}

Aghakouchak, A. and Emad, H.: Application of a conceptual hydrologic model in teaching hydrologic processes, Int. J. Eng. Educ., 26, 963-973, 2010.

Alley, M.: The Craft of Scientific Presentations, New York: Springer-Verlag, 2003.

Alley, M. and Neeley, K. A.: Rethinking the design of presentation slides: A case for sentence headlines and visual evidence, Tech. Commun., 52, 417-426, 2005.

Alley, M., Schreiber, M., Diesel, E., Ramsdell, K., and Borrego, M.: Increased Learning and attendance in resources geology through the combination of sentence-headline slides and active learning measures, Journal of Geoscience Education, 55, 85-91, 2007.

Baker, E. L.: Principles for Scaling Up: Choosing, Measuring Effects, and Promoting Widespread Use of Educational Innovation, in: Scale-up in Education Volume I: Ideas in Principle, edited by: Schneider, B. and McDonald, S.-H., 37-54, Plymouth, UK: Rowman \& Littlefield Publishers, Inc., 2007.

Baraniuk, R. G., Burrus, C. S., Hendricks, B., Henry, G., Hero, A., Johnson, D. H., Jones, D. L., Nowak, R., Odegard, J., Potter, L., Reedstrom, R., Schniter, P., Selesnick, I., Williams, D., and Wilson, W.: Connexions: Education for a networked world, Proc. IEEE Int. Conf. Acoustics, Speech and Signal Processing - ICASSP'02, Orlando, 4, 4144-4147, 2002.

Baraniuk, R. G., Burrus, C. S., Johnson, D. H., and Jones, D. L.: Connexions - Sharing knowledge and building communities in signal processing, IEEE Signal Proc. Mag., 21, 10-16, 2004.

Ben-zvi-Assarf, O. and Orion, N.: A study of junior high students' perceptions of the water cycle, Journal of Geoscience Education, 53, 366-373, 2005.

Beven, K. J.: Rainfall-runoff modeling - The primer, John Wiley \& Sons, LTD, Chichester, UK, 2000.

Beven, K. J.: Rainfall-runoff modeling - The primer, 2nd Edn., John Wiley \& Sons, LTD, Chichester, UK, 2010.

Boynton, M. A. and Hossain, F.: Improving engineering education outreach in rural counties through engineering risk analysis, ASCE J. Prof. Iss. Eng. Ed. Pr., 136, 224-232, doi:10.1061/(ASCE)EI.1943-5541.0000026, 2010.

Bras, R. L.: Hydrology - An introduction to hydrologic sciences, Addison-Wesley Publishing Company, Reading, MA, 1990.

Brooks, K. N., Ffolliott, P. F., Gregersen, H. M., and DeBano, L. F.: Hydrology and the Management of Watersheds, 3rd Edn., Iowa State University Press, Ames, 2003.

Brutsaert, W.: Hydrology - An Introduction, Cambridge University, Cambridge, UK, 2005.

Carlson, C. A.: Field Research as a Pedagogical Tool for Learning Hydrogeochemistry and Science Writing Skills, Journal of Geoscience Education, 47, 150-157, 1999. 
Chow, V., Maidment, D., and Mays, L.: Applied Hydrology, McGraw-Hill, New York, NY, 1988.

de Wet, A. P.: Integrating Field Observations with Physical and Computer Models in an Introductory Environmental-Geology Course, Journal of Geoscience Education, 42, 264-271, 1994.

Dickerson, D., Callahan, T. J., van Sickle, M., and Hay, G.: Students' conceptions of scale regarding groundwater. Journal of Geosciences Education, 53, 374-380, 2005.

Dickerson, D., Penick, J. E., Dawkins, K. R., Sickle, M. V.: Groundwater in Science Education, Journal of Science Teacher Education, 18, 45-61, 2006.

Dingman, S. L.: Physical Hydrology, 2nd Edn., Prentice Hall: New Jersey, 2002.

Doran, G. T.: There's a S.M.A.R.T. way to write management's goals and objectives, Manag. Rev., 70, 35-36, 1981.

Dunne, T. and Leopold, L.: Water in Environmental Planning, W.H. Freeman and Company, New York, 1978.

Dunnivant, F. M., Brzenk, R., and Moore, A.: A Comprehensive Stream Study Designed for an Undergraduate Non-Majors Course in Earth Science, Journal of Geoscience Education, 47, 158-165, 1999.

Eagleson, P. S.: Dynamic Hydrology, McGraw-Hill, New York, NY, 1970.

Eagleson, P. S.: Ecohydrology: Darwinian expression of vegetation form and function, Cambridge University Press, Cambridge, UK, 2005.

Eagleson, P. S., Brutsaert, W. H., Colbeck, S. C., Cummins, K. W., Dozier, J., Dunne, T., Edmond, J. M., Gupta, V. K., Jacoby, G. C., Manabe, S., Nicholson, S. E., Nielsen, D. R., RodriguezIturbe, I., Rubin, J., Smith, J. L., Sposito, G., Swank, W. T., and Zipser, E. J.: Opportunities in the Hydrologic Sciences, National Academy Press: Washington, DC, 1991.

Elshorbagy, A.: Learner-centred approach to teaching watershed hydrology using system dynamics, Int. J. Eng. Educ., 21, 12031213, 2005.

Felder, R. M. and Brent, R.: Understanding student differences, J. Eng. Educ., 95, 57-72, 2005.

Felder, R. M. and Silverman, L. K.: Learning and teaching styles in engineering education, Eng. Educ., 78, 674-681, 1988.

Firth, P.: The importance of water resources education for the next century, J. Am. Water Resour. As., 35, 487-492, 1999.

Garner, J. K., Alley, M., Gaudelli, A., and Zappe, S.: Common use of PowerPoint versus assertion evidence slide structure: a cognitive psychology perspective, Tech. Commun., 56, 331-345, 2009.

Garner, J. K., Alley, M. A., Sawarynski, L. E., Wolfe, K. L., and Zappe, S. E.: Comparison of Learning from Assertion-evidence slides appear to lead to better comprehension and recall of more complex concepts. Paper presented at the Annual Meeting of the American Society of Engineering Education, Vancouver, Canada, 2011.

Groves, J. R. and Moody, D. W.: A survey of hydrology course content in North American universities, J. Am. Water Resour. As., 28, 615-621, doi:10.1111/j.1752-1688.1992.tb03181.x, 1992.

Henderson, C. and Dancy, M. H.: Increasing the Impact and Diffusion of STEM Education Innovations. Invited paper for the National Academy of Engineering, Center for the Advancement of Engineering Education Forum, Impact and Diffusion of Transformative Engineering Education Innovations, available at: http://www.nae.edu/File.aspx ?id=36304 (last access: September 2012), 2010.

Hendricks, E. L.: Hydrology - An understanding of water in relation to earth processes requires collaboration of many disciplines, Science, 135, 699-705, 1962.

Hendriks, M. R.: Introduction to physical hydrology, Oxford University Press, New York, NY, 2010.

Hewlett, J. D.: Principles of forest hydrology, University of Georgia Press, Athens, GA, 1982.

Hornberger, G. M., Raffensperger, J. P., Wiberg, P. L., and Eshleman, K. N.: Elements of physical hydrology, Johns Hopkins University Press, Baltimore, MD, 1998.

Hossain, F. and Huddleston, D.: A proposed computer-assisted graphics-based instruction scheme for stochastic theory in hydrological sciences, Computers in Education Journal, XVII, 16-25, 2007.

Howe, C. W.: Preface to "A Creative Critique on U.S. Water Education", Journal of Contemporary Water Research and Education, 139, 1-2, 2008.

Hudak, P. F.: Groundwater field station for geoscience students, J. Geogr., 98, 23-28, doi:10.1080/00221349908978850, 1999.

Hughes, D. A.: Hydrological education and training needs in subSaharan Africa: requirements, constraints and progress, Hydrol. Earth Syst. Sci., 16, 861-871, doi:10.5194/hess-16-861-2012, 2012.

James, L. D.: An historical perspective on water resources education, Water Resources Update, Universities Council on Water Resources, 91, 19-21, 1993.

Kastens, K. A., Manduca, C. A., Cervato, C., Frodeman, R., Goodwin, C., Liben, L. S., Mogk, D. W., Spangler, T. C., Stillings, N. A., and Titus, S.: How geoscientists think and learn, EOS T. Am. Geophys. Un., 90, 265-266, 2009.

Kavetski, D. and Clark, M. P.: Numerical troubles in conceptual hydrology: Approximations, absurdities and impact on hypothesis testing, Hydrol. Process., 25, 661-670, doi:10.1002/hyp.7899, 2011.

Keller, J.: Is PowerPoint the devil?, Chicago Tribune, 23 January 2004.

King, E. G., O’Donnell, F. C., and Caylor, K. K.: Reframing hydrology education to solve coupled human and environmental problems, Hydrol. Earth Syst. Sci. Discuss., 9, 7739-7759, doi:10.5194/hessd-9-7739-2012, 2012.

LeDee, O., Barnes, R., Emanuel, R., Fisher, P., Henkel, S., and Marlon, J.: Training a New Scientist to Meet the Challenges of a Changing Environment, EOS T. Am. Geophys. Un., 92, p. 135, 2011.

Ledley, T. S.: Recommendations for making geoscience data accessible and usable in education, EOS T. Am. Geophys. Un., 89, p. 291, doi:10.1029/2008EO320003, 2008.

Lee, G. K. and Cole, R. E.: From firm-based to a community-based model of knowledge creation: The case of the Linux kernel development, Organ. Sci., 14, 633-649, 2003.

Lynn Jr., L. E.: Teaching and learning with cases - A guidebook, Chatham House Publishers, New York, 1999.

MacDonald, L. H.: Developing a field component in hydrologic education, Water Resour. Bull., 29, 357-368, 1993.

Manduca, C. A., McMartin, F., and Mogk, D. W.: Pathways to Progress: A Vision and Plan for Developing the National METE Digital Library, available at: http://serc.carleton.edu/files/serc/ 
pathways_progress.pdf (last access: September 2012), 2001.

Manduca, C. A., Baer, E., Hancock, G., MacDonald, R. H., Patterson, S., Savina, M., and Wenner, J.: Making undergraduate geoscience quantitative, EOS T. Am. Geophys. Un., 89, 149-150, 2008.

McGuire, K. J. and Likens, G. E.: Historical roots of forest hydrology and biogeochemistry, in: Forest Hydrology and Biogeochemistry: Synthesis of Past Research and Future Directions, edited by: Levia, D. F., Carlyle-Moses, D., and Tanaka, T., Ecological Studies 216, Springer, Berlin, 3-26, doi:10.1007/978-94007-1363-5_1, 2011.

McMartin, F.: Preliminary findings from science, mathematics, engineering, and technology education user study focus groups, available at: http://www.smete.org (last access: May 2005), 1999.

Merwade, V. and Ruddell, B. L.: Moving university hydrology education forward with community-based geoinformatics, data and modeling resources, Hydrol. Earth Syst. Sci., 16, 2393-2404, doi:10.5194/hess-16-2393-2012, 2012.

Mihelcic, J. R., Paterson, K. G., Phillips, L. D., Zhang, Q., Watkins, D. W., Barkdoll, B., Fuchs, V. J., Fry, L. M., and Hokanson, D. R.: Educating Engineers in the Sustainable Futures Model with a Global Perspective, Civ. Eng. Environ. Syst., 25, 255-263, 2008.

Milano, C.: Go with the flow: a wave of water-related opportunities, Science Careers Magazine, AAAS, 2010.

Milly, P. C., Betancourt, J., Falkenmark, M., Hirsch, R. M., Kundzewicz, Z. W., Lettenmaier, D., and Stouffer, R. J.: Stationarity is dead: Whither water management?, Science, 319, 573574, 2008.

Mogk, D. W. and Lee, Z.: Addressing opportunities and challenges in evaluation and dissemination through creation of a national library for undergraduate science education, Geosciences Information Society Proceedings, 27, 17-22, 1997.

Mollinga, P. P.: Towards the transdisciplinary engineer: incorporating ecology, equity and democracy concerns into water professionals' attitudes, skills and knowledge, Irrig. Drain., 58, S195S204, 2009.

Muramatsu, B.: The development of a national science, mathematics, engineering and technology education digital library: Lessons learned from NEEDS, in: Proceedings of the 2000 International Conference for Engineering Education, 13-17 August 2000, Taipei, Taiwan, 2000.

Muramatsu, B., McMartin, F., and Agogino, A. M.: The development of a national science, mathematics, engineering and technology education digital library: Lessons learned from NEEDS, in: Proceedings of the 2000 Frontiers in Education Conference: October 2000, Kansas City, MO, 2000.

Nash, J. E., Eagleson, P. S., Philip, J. R., and van der Molen, W. H.: The education of hydrologists, Hydrolog. Sci. J., 35, 597-607, doi:10.1080/02626669009492466, 1990.

Pearce, A. R., Bierman, P. R., Druschel, G. K., Massey, C., Rizzo, D. M., Watzin, M. C., and Wemple, B. C.: Pitfalls and Successes of Developing an Interdisciplinary Watershed Field Science Course, Journal of Geoscience Education, 58, 213-220, 2010.

Philip, J. R.: Hydrology and the real world, in: Advances in Theoretical Hydrology: A Tribute to James Dooge, edited by: O'Kane, J. P., Elsevier, Amsterdam, 201-207, 1992.

Prince, M. J. and Felder, R. M.: Inductive learning and teaching methods: Definitions, comparisons, and research bases, J. Eng.
Educ., 95, 123-138, 2006.

Puzniak, J., McMartin, F., and Agogino, A.: Building a digital learning community for faculty on the internet, Proceedings of the 2000 American Society for Engineering Education Annual Conference, St. Louis, MO, 2000.

Rodhe, A.: Physical models for classroom teaching in hydrology, Hydrol. Earth Syst. Sci., 16, 3075-3082, doi:10.5194/hess-163075-2012, 2012.

Salvage, K., Graney, J., and Barker, J.: Watershed-Based Integration of Hydrology, Geochemistry, and Geophysics in an Environmental Geology Curriculum, Journal of Geoscience Education, 4, 141-148, 2004.

Schwenk, J., Hossain, F., and Huddleston, D.: A computer-aided visualization tool for stochastic theory education in water resources engineering, Comput. Appl. Eng. Educ., 14, 1-14, 2009.

Shaffer, C. and Anundsen, K.: Creating community anywhere, Perigree Books, New York, NY, 1993.

Shaw, E. M., Beven, K. J., Chappell, N. A., and Lamb, R.: Hydrology in practice, 4th Edn., Taylor and Francis, New York, NY, 2010.

Shaw, S. B. and Walter, M. T.: Using comparative analysis to teach about the nature of nonstationarity in future flood predictions, Hydrol. Earth Syst. Sci., 16, 1269-1279, doi:10.5194/hess-161269-2012, 2012.

Smith, K. A., Sheppard, S. D., Johnson, D. W., and Johnson, R. T.: Pedagogies of engagement: Classroom-based practices, J. Eng. Educ., 94, 87-101, 2005.

Sopper, W. E. and Lull, H. W.: Streamflow characteristics of physiographic units in the northeast, Water Resour. Res., 1, 115-124, doi:10.1029/WR001i001p00115, 1965.

Thompson, S. E, Harman, C. J., Schumer, R., Wilson, J. S., Basu, N. B., Brooks, P. D., Donner, S. D., Hassan, M. A., Packman, A. I., Rao, P. S. C., Troch, P. A., and Sivapalan, M.: Patterns, puzzles and people: implementing hydrologic synthesis, Hydrol. Process., 25, 3256-3266, 2011.

Trop, J. M., Krockover, G. H., and Ridgway, K. D.: Integration of field observations with laboratory modeling for understanding hydrologic processes in an undergraduate earth-science course, Journal of Geoscience Education, 48, 514-521, 2000.

Tufte, E. R.: The cognitive style of PowerPoint, Cheshire, CT: Graphics Press, 2003.

United Nations Educational, Scientific and Cultural Organization (UNESCO): Teaching aids in hydrology, edited by: Moore, W. L., The UNESCO Press, Paris, France, 1972.

United Nations Educational, Scientific and Cultural Organization (UNESCO): The teaching of hydrology, Technical Papers in Hydrology 13, The UNESCO Press, Paris, France, 1974.

United States National Research Council: Opportunities in the Hydrologic Sciences, National Academy Press, Washington, DC, 1991.

van Vuren, G., Liebrand, J., and Vincent, L.: Debating the Water Professional of Tomorrow, Irrig. Drain., 58, S162-S167, 2009.

Wagener, T. and McIntyre, N.: Tools for teaching hydrological and environmental modeling, Computers in Education Journal, XVII, 16-26, 2007.

Wagener, T., Gupta, H. V., Carpenter, K., James, B., Vazquez, R., Sorooshian, S., and Shuttleworth, J.: A hydroarchive for the free exchange of hydrological software, Hydrol. Process., 18, 389391, doi:10.1002/hyp.5216, 2004. 
Wagener, T., Weiler, M., McGlynn, B., Marshall, L., McHale, M., Meixner, T., and McGuire, K.: Taking the pulse of hydrology education, Hydrol. Process., 21, 1789-1792, doi:10.1002/hyp.6766, 2007.

Wagener, T., Sivapalan, M., Troch, P. A., McGlynn, B. L., Harman, C. J., Gupta, H. V., Kumar, P., Rao, P. S. C., Basu, N. B., and Wilson, J. S.: The future of hydrology: An evolving science for a changing world, Water Resour. Res., 46, W05301, doi:10.1029/2009WR008906, 2010.

Wampler, J. M.: Misconcepts - a column about errors in geoscience textbooks: Misconceptions of ground-water's capillary fringe, Journal of Geoscience Education, 45, 460-462, 1997.

Wampler, J. M.: Misconceptions - a column about errors in geoscience textbooks: confusion about the role of infiltration in the hydrologic cycle, Journal of Geoscience Education, 48, 382-385, 2000 .
Ward, A. D. and Trimble, S. W.: Environmental Hydrology, 2nd Edn., Lewis Publishers, 2003.

Whiteman, W. and Nygren, K. P.: Achieving the right balance: properly integrating mathematical software packages into engineering education, J. Eng. Educ., 89, 331-336, 2000.

Wilm, H. G.: The training of men in forest hydrology and watershed management, J. Forest., 55, 268-272, 1957.

Zimmerman, E.: Fresh starts - Hiring in hydrology resists the slump, New York Times, The New York Times Company, New York, 2009. 